\title{
La grieta del sistema: Hölderlin entre Schelling y Deleuze
}

\author{
The crack of system: Hölderlin \\ between Schelling and Deleuze
}

\author{
Amanda NúÑEZ GARCÍA \\ (UNED)
}

Recibido: 28/10/2011

Aceptado: 19/04/2012

\section{Resumen}

El presente artículo propone un discurso indirecto libre entre el pensamiento de G. Deleuze y los de Schelling y Hölderlin a través de las síntesis del tiempo deleuzeanas. Desde el criticismo contemporáneo notamos que la filosofía de Deleuze es heredera del idealismo de Schelling o, más bien, de su grieta. Sin embargo, mostramos cómo sin Hölderlin no es posible ni la grieta del sistema de Schelling ni la apertura al por-venir. Por-venir es como llama Deleuze a la tercera síntesis del tiempo o al espacio del virtual; posibilidad de que haya algo nuevo: el acontecimiento.

Palabras clave: Schelling, Deleuze, Hölderlin, sistema, grieta, univocidad, inmanencia.

\begin{abstract}
The aim of this article is to create an open, albeit indirect, dialogue between the thought of G. Deleuze and that of Schelling as well as that of Hölderlin, via Deleuze's syntheses of time. From the point of view of contemporary studies we establish that Deleuze's philosophy is heir to the idealism of Schelling, or, rather, to the breach in the schellingian edifice. We also show, however, that without Hölderlin is not possible neither the breach in the system of Schelling nor the opening to the to-come. To-come is the name which Deleuze call the third synthesis of time or the space of the virtual, the possibility of something new: the Event.
\end{abstract}

Keywords: Schelling, Deleuze, Hölderlin, system, crack of, univocity, inmanence. 


\section{Introducción y criticismo}

Existe un amplio criticismo contemporáneo que tiende a acercar el pensamiento de Gilles Deleuze al idealismo a partir de una lectura de la Univocidad deleuzeana como el establecimiento de un Uno-Todo. Podríamos convenir que esta corriente es iniciada por Alain Badiou en su libro sobre el filósofo: Deleuze. El clamor del $\operatorname{ser}^{1}$ y que ha tenido múltiples sucesores hasta el punto de que prácticamente toda la bibliografía secundaria sobre el filósofo francés da cuenta de ello, muchas veces a favor de esta tesis.

Sin menospreciar el interés de esta corriente, resulta empero poco productiva por cuanto intenta mostrar que Deleuze es un idealista, lo cual está fuera completamente del sistema deleuzeano y quizá tenga consecuencias más ideológicas que filosóficas o políticas. Encontramos, sin embargo, lecturas menos sesgadas y más complejas al respecto de este acercamiento entre Deleuze y el idealismo que no intentan subsumir el pensamiento deleuzeano en una identidad con otros pensamientos, sino hacer notar las resonancias posibles para bien de las dos filosofías que tratan. En esta corriente de discurso indirecto libre encontramos diversos casos muy interesantes y productivos. Destacamos aquí, por un lado, la tarea de JeanChristophe Goddard quien aproxima el pensamiento de Deleuze al de Fichte a partir de la cuestión esencial de la imagen y la simplicidad²; por otro lado, el acercamiento del pensador francés al idealismo trascendental -más de corte kantiano-que José Luis Pardo muestra en muchas de sus obras 3 y, por supuesto, el artículo de Alberto Toscano: «Philosophy and the Experience of Construction» ${ }^{4}$. Este último texto se puede concebir como el lugar donde se comienza a pensar muy lúcidamente la relación entre Schelling y Deleuze retomando el pensamiento de G. Simondon ${ }^{5}$. No podemos centrarnos ahora con rigor en todas estas líneas de inves-

\footnotetext{
${ }^{1}$ Badiou, A.: Deleuze. El clamor del ser. Manatial, Buenos Aires, 1997. Esta corriente podría envolver a Bergen, V.: L'ontologie de Gilles Deleuze, Paris, L'Hartman, 2001, Gualandi, A.: Deleuze. Colección: Figures du Savoir Paris: Les Belles Lettres, 1998; y gran parte del criticismo actual sobre el pensamiento de Deleuze. Por otra parte, encontramos aquellos pensamientos que lo desligan como es el de Pardo, J. L. en Las formas de la exterioridad. Valencia, Pre-textos 1992 ; Sobre los espacios. Pintar escribir, pensar. Barcelona, Serbal, 1991 o el texto de García, R.: La Anarquia Coronada: La Filosofia de Gilles Deleuze, Colihue, Buenos Aires, 1999.

2 Goddard, J-Ch.: Mysticisme et folie: Essai sur la simplicité. Desclée de Brouwer, 2002.

3 Pardo, J. L.: La regla del Juego. Sobre la dificultad de aprender filosofía. Galaxia Gutenberg, Barcelona 2004. Y “"Máquinas y componendas. La filosofía política de Deleuze y Foucault”. En López Álvarez, P. y Muñoz, J. (Eds.), La impaciencia de la libertad. Michel Foucault y lo político, Madrid: Biblioteca Nueva, 2000. (pp. 23-84) Y Prólogo "Del ser en cuanto devenir" al libro de Franco, L.: Gilles Deleuze. Sentido y Acontecimiento. Madrid. Eds. Antígona. 2011 Passim.

4 Toscano, A.: "Philosophy and the Experience of Construction" en Norman, J. \& Welchman, A. (Eds.): The New Schelling, Continuum, London, New York, 2004. pp. 106-127.

5 Simondon, G.: L'individu et sa genèse physico-biologique. Paris: PUF, 1964.
} 
tigación por importantes que puedan ser a la hora de establecer las constelaciones de nuestro artículo. Atenderemos sólo al último de ellos.

Podemos decir que nuestro artículo se centra en la vía abierta por A. Toscano y continuada, en trazos importantes, por J. L. Pardo y L. Franco ${ }^{6}$. Pero, dentro del discurso indirecto libre que el presente escrito elabora, encontramos varios factores de diferencia. En primer lugar, expondremos cómo la relación de Deleuze con Schelling se establece, además de por la noción de "construcción", a través de la grieta o la fisura que aparece en el pensamiento del filósofo alemán como novedad en la corriente idealista 7 ; pero incidiremos en cómo la postura filosófica que cabe reivindicar como antecesora y productora de esta grieta y la que precisamente establece la relación puramente con Deleuze no es tanto un idealismo, fisurado o no, sino el pensamiento de F. Hölderlin.

\section{Schelling: Grieta y Construcción}

Alberto Toscano enlaza las filosofías de Deleuze y de Schelling a través de la noción de "construcción" que vemos aparecer en los textos de Schelling: El Sistema del idealismo trascendental de $1800^{8}$ y es proseguida en el artículo de 1803, "Construcción en Filosofía"9. Esta noción hace notar la importancia que el filósofo alemán da a la producción o construcción del Sistema. Si en estos textos tempranos de Schelling todavía se trata de una génesis lógica al modo del idealismo postkantiano, esto es, a partir de un principio idéntico, en Las edades del mundo ${ }^{10}$ y sus tres escrituras notamos cómo transmuta hacia la noción de una "intuición productiva" puramente orgánica ${ }^{11}$. Una intuición que funciona a modo de ausencia o de fondo sin fondo (Ungrund) donde no se halla, como notaremos más adelante, ni un principio de identidad, ni de reflexión, ni tan siquiera una acción positiva. Esta noción de construcción de los escritos posteriores de Schelling se acerca a la noción deleuzeana de plan(o) de inmanencial2. Es en esta zona donde

\footnotetext{
6 Vid. Franco, L.: Gilles Deleuze. Sentido y Acontecimiento. Op. Cit..

7 Vid. Duque, F.: Historia de la Filosofía Moderna. La era de la Crítica, Akal, Madrid, 1998. Así como Martínez Marzoa, F.: Historia de la Filosofia II. Istmo, Madrid, 1994.

8 Schelling, F. W. J.: Sistema del idealismo trascendental, Anthropos, Barcelona, 1988. Traducción, prólogo y notas de J. Rivera de Rosales y V. López-Domínguez.

9 Schelling, F. W. J.: Schellings Werke (SW), V.

10 Schelling, F. W. J.: Las edades del Mundo. Akal, Madrid, 2002.

$11 \mathrm{Op}$. Cit. las tres introducciones de la obra.

12 Traducimos el concepto deleuzeano "plan d'inmanence" por "plan(o) de inmanencia" para hacer notar, en cada caso, que la palabra francesa "plan" posee dos acepciones a la vez: la de "plano" como un mapa, una tierra donde orientarse, o un plano geométrico o geológico; y la de "plan", como diríamos en "tengo un plan", también una orientación pero, en este caso, de la acción. Vid. Núñez, A.: Gilles Deleuze. Una ontología estética menor, Dykinson, Madrid, en prensa.
} 
Toscano localiza una deriva materialista de Schelling frente al idealismo; pues, si podemos pensar con Deleuze que el plan(o) de inmanencia es a la vez "materia del ser e imagen del pensar"13, queda rota la supremacía de la idea abstracta sobre la materia, de la lógica sobre lo real14.

La inmanencia que sostiene esta "construcción", la cual no da lugar a subordinación alguna, genera un sistema que podríamos llamar de multiplicidad única, pues en lo vivo primigenio de Schelling la diferencia no confiere escisión alguna. Por ello necesidad y libertad, luz y oscuridad, afirmación y negación poseen una distinción real y formal pero no numérica ${ }^{15}$. Es decir, al eliminar el principio positivo del sistema -ya sea éste acción subjetiva productiva o principio lógicoSchelling se acerca al pensamiento materialista de Spinoza puesto que conlleva una localización y distinción de los ámbitos para una no confusión, pero lo hace de un modo inmanente y univocista, es decir, sin separación numérica. No se da distinción numérica ni entre los aparentes contrarios sentido-sinsentido, luz-oscuridad, etc., ni entre ellos y el principio. Por lo tanto, siendo sólo una instancia aquello vivo primigenio que es una ausencia o Ungrund, es, a la vez, varias facetas inseparables que no son otra cosa que la unidad misma en lo que tienen de ausentes, de fondo, de grieta en ellos. Ello provoca una ruptura de la lógica positiva. De un "Uno" nunca se genera un "dos" sino que ya hay una multiplicidad constitutiva, y esa multiplicidad misma es la unidad ya no positiva sino como retirada de todo ente, de todo "Uno".

\section{La crítica de Hölderlin al idealismo o el potencialismo de Schelling}

Ahora bien, para llegar a esta tesis en la que Schelling y Deleuze comparten una univocidad inmanente debemos dar un rodeo para notar por qué podríamos decir con Toscano que hay una cercanía entre Deleuze y Schelling más profunda que entre el filósofo francés y cualquier otro sistema de entre los que solemos llamar idealistas (alejándole sobre todo de Hegel, a quien Deleuze recusa una y otra vez). Esta cercanía es, sin duda, la que se deriva de la crítica que Hölderlin hace al idealismo fichteano y que, según palabras de F. Martínez Marzoa16, obliga tanto a

13 Deleuze, G. y Guattari, F.: Qu'est-ce que la philosophie? Paris: Minuit, 1991. p. 52. Trad. Cast. ¿Qué es la filosofia?, Anagrama, Barcelona, 1993, p. 54. En todas las citas de Deleuze aportamos la paginación del original francés y del castellano si bien la traducción es propia.

14 Vid. Althusser, L. Para un materialismo aleatorio. Ed. Arena Libros, Madrid, 2002.

15 Para la cuestión de las distinciones: formal, modal, real, numérica; Vid. Deleuze, G.: Spinoza et le problème de l'expression. Paris: Minuit, 1968, págs. 165-166. Trad. Cast. Spinoza y el problema de la expresión, Barcelona, Muchnik Editores, 1996, p. 177. Y Núñez, A.: Gilles Deleuze. Una ontología estética menor. Op. Cit.

16 Martínez Marzoa, F.: De Kant a Hölderlin, Visor, Madrid, 1992 y Hölderlin y la Lógica hegeliana. Visor, Madrid, 1995. Passim. 
Schelling como a Hegel a intentar recuperar un idealismo salvando el obstáculo que su gran amigo Hölderlin les ofrece.

El argumento de Hölderlin en el texto nombrado como "Juicio y Ser" de sus Ensayos es el siguiente:

Ser- expresa la ligazón del sujeto y el objeto. Allí donde sujeto y objeto están unidos pura y simplemente, no sólo en parte, allí donde, por lo tanto, están unidos de modo que absolutamente ninguna partición puede ser efectuada sin preterir la esencia de aquello que debe ser pura y simplemente, como ocurre en el caso de la intuición intelectual.

Pero ese ser no debe ser confundido con la identidad. Cuando digo "Yo soy yo", entonces el sujeto (Yo) y el objeto (yo) no están unidos de tal manera que ninguna separación pueda ser efectuada sin preterir la esencia de aquello que debe ser separado; por el contrario, el yo sólo es posible mediante esta separación del yo frente al yo. ¿Cómo puedo decir "¡Yo!" sin conciencia de mí mismo?, pero ¿Cómo es posible la conciencia de mí mismo? Es posible porque yo me pongo enfrente $[\ldots]$ me separo de mí mismo y, pese a esta separación, en lo puesto enfrente me reconozco como lo mismo. [...] Por lo tanto, la identidad no es la unión del objeto y el sujeto que tuviera lugar pura y simplemente; por lo tanto, la identidad no es $=$ el ser absoluto. ${ }^{17}$

Ya notamos cómo este argumento encierra una crítica furibunda al fundamento como identidad fija así como a la reflexión. Pues toda reflexión e identidad, al generar un fundamento fijo y hacerlo separarse de sí mismo para reflexionarse, genera ya una dicotomía y, por lo tanto, no puede hacerse cargo de un ser absoluto. Es más, este esquema reflexivo omitiría la naturaleza misma de lo absoluto que consiste en aquello en lo que no puede haber Ur-Teil (juicio), esto es, partición alguna por tratarse de lo simple.

No podemos introducirnos en la solución que aporta Hegel a este problema, pero podemos acercarnos sucintamente a la solución de Schelling, diametralmente opuesta para Deleuze al racionalismo hegeliano por dejar éste "todo" en el terreno de la representación, subsumiendo toda diferencia en una oposición que será superada finalmente en una identidad positiva, un "Uno"18.

Schelling, en cambio, en su búsqueda de un Ser absoluto simple, ya en las Conferencias de Stuttgart ${ }^{19}$ y en Las edades del mundo (1810-1833) comienza a indagar alternativas a la identidad y al fundamento idéntico; por ello hacer notar la noción de un ser primigenio que es esta grieta, Ungrund o ausencia mencionadas.

\footnotetext{
17 Hölderlin, F.: Ensayos, Madrid, 1997. p. 28. Prólogo, traducción y notas de Felipe Martínez Marzoa. 18 Deleuze, G.: Différence et répétition. PUF, Paris, 1968. pp. 243, 353. Trad. Cast. Diferencia y repetición. Buenos Aires: Amorrortu, 2002, p. 284, 404 y ss.

19 Schelling, F. W. J.: Stuttgarter Privatvorlesungen. Versión inédite, acompagnée du texte des Oeubres, ed. M. Vetö, Turín, Bottega d'Erasmo, 1973.
} 
Que no sea positivo, es decir, que no sea ni un "ente" ni un "uno", no entraña que sea pura negatividad como sí parece haber defendido Hegel. Así, Schelling repite la siguiente frase desligándose de la corriente idealista: «Los idealistas habian confundido lo no-ente con la nada»20

Ahora bien, esta grieta como ser primigenio que no es ni "positum" (Fichte) ni tiene que ver con la "nada" (Hegel), es, sin embargo, una afirmación, pura potencia activa sin ser positiva. Como aclara Deleuze en Diferencia y repetición:

[...] Es Schelling quien hace salir la diferencia de la noche de la identidad con relámpagos más finos, más terroríficos que los de la contradicción: con progresividad. La cólera y el amor son las potencias de la idea que se desarrolla a partir de un mē ón es decir, no una negatividad o un no-ser (oúk ón), sino de un ser problemático o de un noexistente, un ser implícito de las existencias más allá del fundamento. ${ }^{21}$

Así, de este fondo o grieta problemático, ser o vivo primigenio -es decir, que no posee identidad, positividad, negatividad ni reflexión sino que se establece como problema o cuestión- se generarían, sin partición, las diferencias a partir de las potencias diferenciantes mismas de ese fondo, de la potencia con dos caras que es ese fondo mismo. Una potencia sin ente que la determine de antemano, siendo ella la determinación misma.

Esta consideración del vivo primigenio y de las potencias es la zona del pensamiento schellingniano que más interesa a Deleuze y, en cierto modo, es la senda que continúa el filósofo francés en una parte muy explícita de su sistema, lo que llama la segunda síntesis del tiempo y la individuación. Deleuze toma enteramente a Schelling (vía G. Simondon) para presentar la individuación o la génesis estática (que no tiene por qué conllevar historia dinámica progresista pues no actúa como negación y sí aconteceres) ${ }^{22}$. La individuación es el modo de proceder de la potencia de Schelling y está unida a la segunda síntesis del tiempo (el pasado sin subordinación a un presente-ente) en Deleuze $23 \mathrm{y}$, en cierto modo, en tanto que es construcción, al plan(o) de inmanencia como ya vimos con Toscano.

\footnotetext{
20 En todas las primeras partes de Schelling, F. W. J.:Las edades del Mundo.

21 Deleuze, G.: Différence et répétition. Op. Cit. p. 246-247. Trad. Cast. 287-288. Vid. También Schelling, F. W. J.: Las edades del mundo, [221] p. 183-184.

22 Deleuze, G.: Curso sobre Spinoza, 9/12/1980. En medio de Spinoza, Buenos Aires. Cactus, 2003. p. 49. y Deleuze, G.: « Gilbert Simondon: L'individu et sa genèse physico-biologique» en L'île Déserte et autres textes. Textes et entretiens 1953-1974. Minuit, Paris, 2002. pp. 120-125.

23 Para la cuestión esencial de las tres síntesis del tiempo que no podemos tratar aquí en su versión deleuzeana más que tangencialmente, Vid. Deleuze, G.: Diferencia y repetición, El Bergsonismo; así como la magistral explicación de las tres síntesis en el libro de Franco, L.: Sentido y acontecimiento, "segunda parte: Pensar o representar" Op. Cit. págs. 89-113.
} 
No parece haber entonces en Schelling una identidad fracturada como la denunciada por Hölderlin en el sistema de Fichte, sino un fondo problemático, inexistente y potencial (unidad con distinción real y formal) que generaría incluso la representación misma por distinciones modales posteriores. No habría ese "Uno" del cual se generaran los demás números extensamente o ese "Uno" final que los recogería en un sentido último, sino que el fondo o la grieta funcionarían más bien -y forzando el pensamiento de Schelling hacia Spinoza o el último Schelling-como un "cero". Por lo tanto, los diferentes grados potenciales que explica Schelling respecto de la potencia-fondo o potencia $=0$; es decir los grados $A, A 2, A 3$, serían lo mismo que los números al número cero intensivamente. Esto es, si consideramos el cero como número y como no número a la vez, y no lo tratamos como una "nada" ya criticada sino como un "no número determinado", como pura potencia o pregunta implícita, podemos comprender que todos los números siempre son, a la vez que su determinación, la huella del determinador. El cero se conserva y subsiste en todos los números como la muerte acompaña y problematiza a todo ente, como el fondo acompaña a toda la historia, como lo oscuro acompaña a toda luz ${ }^{24}$. No es un origen ni un final, sino que es origen y final porque siempre está con nosotros, insistiendo a todo lo ente. La determinación siempre acompaña a lo determinado como la potencia acompaña a toda potencia determinada.

Ahora bien, no se puede considerar el sistema numérico que defendemos como extenso. En el momento en el que ello se hace y se da una homogeneidad espacial a los números como partes de un todo (que sería más bien un Uno que se parte a sí mismo y no un cero que insiste y no existe), todo este sistema de potencias caería en la representación y volveríamos al mismo problema de la identidad, el fundamento y la reflexión que queríamos eliminar con Schelling. Al contrario, como Deleuze dice en sus cursos sobre Kant, hay un modo de los grados de potencia que es sólo intenso. La luz (como en el modelo neoplatónico), la temperatura o la velocidad contemplan estas magnitudes intensivas que se individúan en grados sin que haya homogeneidad entre ellos, sin que sean descomponibles pues no sólo es simple el fondo o cero de esa potencia, sino también todos sus grados. Según un ejemplo que traza Heidegger en La pregunta por la cosa, si tenemos una temperatura de 30 grados, ella no es la suma de tres veces diez grados ${ }^{25}$. Es decir, una habitación que esté a $30^{\circ}$ es cálida y nunca equivale a la suma de tres habitaciones de $10^{\circ}$ cada una. Esto es, la diferencia cuantitativa de la potencia genera diferencias cualitativas indescomponibles. Como expone Heidegger:

\footnotetext{
24 Vid. esta cuestión en torno a lo temporal en Carrasco, A.: «El sistema de los tiempos y el epos de la historia: Schelling y la historicidad del absoluto.» en Bajo Palabra, Revista de filosofía II Época, n.4. 2009. Si bien Schelling se acerca al límite a esta noción de cero, sobre todo al final de su pensamiento, sin embargo, y sobre todo en esta obra: Las edades del mundo, sigue pivotando en torno a la unidad-plenitud. Es M. Heidegger quien explicita la cercanía creciente a un cero que no es una nada. 25 Cfr. Deleuze, G.: Curso sobre Kant, 14/3/78.
} 
Un tono fuerte, por ej., no está compuesto de un determinado número de tonos, sino que desde el tono débil hasta el fuerte hay un escalonamiento de grados. Las multiplicidades de la unidad de intensidad son muchas unidades momentáneas. Las multiplicidades de la unidad de una extensión son en cada caso unidades particulares de una multiplicidad. Sin embargo ambas, intensidad y extensión se pueden coordinar, en cuanto cantidades, con números. Pero con ello los grados de las intensidades no se convierten en un mero agregado de partes. ${ }^{26}$

Así parece actuar la individuación de la grieta-potencia schellingniana, por progresión discontinua frente a, por ejemplo, la oposición hegeliana. Como dice también Heidegger en este texto, la intensidad y la extensión o representación se pueden coordinar, de este modo en el sistema de Schelling no quedan eliminadas las instancias de sujeto y objeto sino que serían posteriores modulaciones -hijas y madres de la representación-reflexión-de estas potencias que se ejercen como tales en su acción diferenciadora.

Esta solución schellingniana se acerca a un spinozismo univocista de la sustancia que es inmanente a sus modos pero no los prefigura de antemano como sí lo harían los conceptos extensos y muertos (las figuras-formas). De tal modo que, como dice Deleuze, estarían más cercanos en esencia un buey (ya que, según Hegel, de vacas grises se trata) y un caballo de tiro que este mismo caballo de tiro y un caballo de carreras ${ }^{27}$. Es decir, la esencia se definiría por la potencia y los grados del absoluto productivo más que por un esquema previo de la reflexión que debe doblarse en oposiciones desde el comienzo, aniquilando la simplicidad de lo absoluto. Si esto segundo se propone, ya sabemos que aniquila todo ser o todo absoluto-simple tratándolo como un uno-todo extenso donde ya siempre se da una partición originaria (Ur-Teil).

Con esta operación Schelling se libera de un idealismo racionalista de la reflexión pudiendo cumplir con un sistema que no adolezca del problema que el joven Hölderlin ya había anunciado respecto del sistema de Fichte. Y ello lo consigue gracias a una grieta o fisura de ese mismo sistema, un ser primigenio como fondo o cero, pues, como dice Deleuze en Diferencia y Repetición: «Así como la diferencia reúne y articula inmediatamente lo que distingue, la fisura retiene aquello que fisura» ${ }^{28}$. Conservar la simplicidad del ser se consigue gracias a una grieta sistemática o fondo inexistente.

De esta manera el constructivismo del joven Schelling al que apela Toscano devendría un constructivismo material y, como Schelling mismo dice, orgánico y

\footnotetext{
26 Heidegger, M.: La pregunta por la cosa. La doctrina kantiana de los principios trascendentales. Buenos Aires, Ed. Sur, 1964. p. 205.

27 Deleuze, G. \& Parnet, C.: Dialogues. Paris: Flammarion, 1996. Trad. Cast. Diálogos. Valencia: Pretextos, 1997, p. 70.

28 Deleuze, G.: Différence et répétition. p. 220, Trad. Cast. p. 260.
} 
vivo completamente, pues se acerca más a la constitución de un animado desde su líquido amniótico que a una construcción lógica muerta y abstracta.

\section{Entre el cero y el uno}

Pero en Schelling todavía encontramos, según Deleuze, un problema con la representación; un problema quizá demasiado ligado a lo orgánico mismo. Este es el punto en el cual el sistema schellingniano y el deleuzeano se alejan, pues Deleuze encuentra en él un resquicio de idealismo. Dice Deleuze en Diferencia y Repetición:

Para la representación, es preciso que toda individualidad sea personal (Je), y toda singularidad individual (Moi). Allí donde se cesa de decir Yo (Je), también cesa por consiguiente la individuación, y allí donde la individuación cesa, cesa también toda singularidad posible. Es forzoso, desde ese momento, que el sin fondo se represente desprovisto de toda diferencia, ya que no tiene individualidad ni singularidad. Esto también se ve en Schelling, en Schopenhauer y hasta en el primer Dyonisos, el del Nacimiento de la tragedia: su sin fondo no soporta la diferencia. ${ }^{29}$

En efecto, parece que Schelling finalmente, y a pesar de haber agrietado sistemáticamente el sistema, no se desprende de la cerrazón del mismo, de la cerrazón a la que obliga la representación, del Uno. Por lo cual, algo queda establecido de antemano, algo a lo que todo lo demás debe quedar subordinado. Ello funda un dominio y un poder sobre lo ontológico así como una estructura en el ser a imagen y semejanza de la nuestra. Es decir, se calca el plano óntico e incluso antropológico sobre el ser debido a que es esto óptico lo que nos da seguridad y podemos preveer, pero con ello se impiden nuevas combinatorias, otros modos de vida. Se reprimen entonces las posibilidades abiertas de futuros (tercera síntesis del tiempo), así como toda apertura a un espacio político que no sea de dominio, juicio y coacción. De este modo, Schelling no acaba de separarse de un intento de equilibrio perdido, pues este fondo oscuro y sin fondo, mirado del lado de la representación y el sujeto, sólo es un caos y es terrible, acaba siendo algo más parecido a un no-ser que debe ser organizado y reprimido. Estos problemas demasiado idealistas, que proyectan un programa y juzgan a lo real, aparecen por varias cuestiones simultáneas.

En primer lugar, por no poder separarse, por muchos intentos que se realicen, de un "Uno", de un "Uno" como fin o plenitud respecto del cual el cero sería un fondo peligroso, caótico, irracional y desgraciado de la historia. Se trata de una no asunción de la muerte que nos quita la posibilidad misma de crear lo nuevo. La muerte, al igual que el cero, considerada sólo como trascendencia y no de forma inmanente como aquello que acompaña todos los grados de ser siempre, nos deja-

29 Op. Cit. p. 354. Trad. Cast. p. 408. 
ría en el todo o la nada, no cabría la posibilidad de la resurrección en otras combinatorias y, con ello, cerraría el que se pudieran encontrar otros mundos en lo ya dicho y ya hecho. El pasado quedaría clausurado en sí mismo; y ello debido al sistema del idealismo que subordina y reduce toda espacialidad, todo afuera que no puede ser controlado, a la forma de la interioridad que es el tiempo ${ }^{30}$.

$\mathrm{Y}$, en segundo lugar, y debido a la cuestión del tiempo organizador como forma de la interioridad, al no separarse tampoco de un ideal humano y sus representaciones como finalidad del sistema.

Por un lado, entonces, ha de establecerse un fin, un "Uno" trascendente que rija sobre el caos. Si bien ese "Uno" es complementado con el "cero", sin embargo queda establecido, como en el neoplatonismo, la diferencia entre lo que queda más cerca del "Uno" y, por lo tanto es "mejor", y lo que se acerca más al "cero", que es caótico y monstruoso. Por otro lado, ese fin está dado de antemano, es decir, clausura el sistema. Como cualquier intervalo está encerrado entre el cero y el uno su principio, que es su fin, no puede cambiar de naturaleza. Y esto es así porque está fabricado a imagen y semejanza del sujeto, por lo que no acepta de buena gana, sólo como resto o drama, cualquier afuera del sistema mismo. Dice Alberto Toscano al respecto:

En cuanto el principio no es susceptible de ser construido, la filosofía es siempre ya inmanente al Absoluto, cualquier exterioridad no-filosófica desaparece. La construcción en Schelling no tiene exterior. Se construye a ella misma en el interior del Absoluto, y garantiza esta operación por una inmanencia a la posterior unidad orgánica. [...]

Es en este aspecto que el materialismo de Deleuze-Guattari, el cual interpone el trazado de un plano de inmanencia entre la construcción del concepto y la salvaje multiplicidad del caos no filosófico, rompe el círculo reflexivo que caracteriza la imagen orgánica del pensamiento. Su insistencia en la heterogénesis es apuntada precisamente al desemparejar la inmanencia de la necesidad y la construcción de la interioridad. 31

Por ello, Deleuze no puede seguir ese camino y se separa radicalmente Schelling, conduciéndose hacia una inmanencia que no sea "inmanente" a otra cosa, lo cual establecería ya una trascendencia como hace notar en ¿Qué es la filosofia? y en su último artículo: "La inmanencia... una vida". Y ello porque si algo es inmanente a algo otro, esto otro queda como su ente soberano y trascendente, su polo de referencia separado y dado de antemano. El sistema de la grieta schellingniano por mucha fisura que establezca, no llega a tocar el afuera en su afirmación y no termina de salir de la representación, es decir, de la identidad, la semejanza, la negación y la oposición 32 .

30 Vid. Pardo, J. L.: Las formas de la exterioridad. Pretextos, Valencia, 1992.

31 Toscano, A.: "Philosophy and the experience of construction" p. 124.

32 «No adquiere el poder de afirmar ni la divergencia ni el descentramiento. Necesita un mundo convergente, concéntrico; un mundo donde sólo aparentemente se está ebrio, donde la razón simula estar 
El sistema schellingniano parece curvarse y convertirse en una suerte de ciclicidad donde se encuentra, como culminación, el sujeto y la reflexión en un absoluto dado de antemano e interior (es decir, sólo temporal). La construcción tendría un fundamento (aun en la ausencia del mismo ${ }^{33}$ ) que no podría ser alterable, por lo que su constructivismo quedaría viciado en el espacio de posibilidad cerrado entre el cero y el uno. El sistema de Schelling finalmente no permitiría que lo divergente, lo nuevo, lo azaroso del aquí y del ahora viniera a cambiar el estado de las cosas que hay de hecho. No sería entonces -al igual que en la crítica que Deleuze hace a Kantmás que una justificación de derecho de lo que hay de hecho...y de un modo quizá más cruento que en Kant, pues justificaría también el horror, los cadáveres y los vicios de la historia que seguiría su paso con una conciencia doble: satisfecha de su evolución orgánica por un lado, a la par que cargada por sus muertos por el otro. Dicho sistema justificaría finalmente todo el pasado fijo y sin posibles en una teodicea al tiempo que asfixiaría todo futuro y toda política.

\section{Hölderlin o la apertura del por-venir}

La tesis schellingniana de Las edades del mundo - muy acertada a ojos de Deleuze y en muchos puntos heredable por cuanto establece cierta univocidad inmanente gracias a una grieta sistémica- no es sin embargo, suficientemente inmanente. Es decir, cae en la ilusión trascendental de una nueva trascendencia, en una teodicea cruel que elimina la posibilidad de lo político, de poder cambiar lo que hay o deslegitimarlo. Es por esta razón, y en orden a poder establecer un por-venir y una verdadera política en lugar de una mera gestión de lo que hay y sus sufrimientos necesarios, por lo que Deleuze retorna a la crítica que Hölderlin hace al idealismo. Y no retorna sólo a su crítica, sino a la grieta o fisura que establece Hölderlin como el sistema mismo. Para establecer un por-venir es necesario un afuera, que la grieta ya sea el afuera mismo de manera que un poco de aire fresco y un poco de diferencia puedan incidir en lo que hay y no se dé siempre lo "mismo bajo el cielo" del Eclesiastés, sino que podamos encontrar "lo nuevo sobre la tierra" e incluso, en cierto modo, provocarlo; para que haya acontecimiento y haya política: otros modos de vida.

Hölderlin, desde su primera crítica a Fichte, lo que busca es la solución a un principio identitario como fundamento, y lo hace, por lo ya expuesto, alejándose de

ebria y canta un aire dionisiaco, pero aún es razón "pura". Porque la razón suficiente, o el fundamento, no son otra cosa que el medio para hacer reinar lo idéntico sobre el mismo infinito, y para hacer penetrar en el infinito la continuidad de semejanza, la relación de analogía, la oposición de los predicados.» Deleuze, G.: Différence et répétition. p. 339, Trad. Cast. p. 391.

33 Vid. Deleuze, G. \& Guattari, F.: Mille plateaux, Capitalisme et schizophrénie tome 2. Paris: Minuit, 1980. Trad. Cast. Mil mesetas, Capitalismo y esquizofrenia 2. Valencia: Pre-textos. 1997. pp. 343-346. 
una identidad o fin final asintótico, así como de otro "uno" y de otra trascendencia. Donde lo encuentra es en una exterioridad al sistema: un espacio frente a la interioridad del mero tiempo. Hölderlin busca una grieta sistémica no viciada de "Uno" ni de tiempo-interioridad. Busca un afuera que libere al sistema y a la vida misma de su encerramiento, encontrado salidas hacia el por-venir y la política. Por ello debe salir de la lógica de los fines dados de antemano, así como de la estricta necesidad fáctica del pasado que se narra y de la organicidad de este absoluto cerrado en sus abismos y sin posibilidad de alteración donde terminaba Schelling.

Es decir, la búsqueda de Hölderlin se centra en un afuera que haga y deshaga al sistema sin cosificación alguna dada de antemano. Y ello debido a que es la salida frente a muchas de las características de la "reflexión" criticadas ya por el joven Hölderlin al idealismo a partir de Fichte. Pues la reflexión, como vimos, ya supondría un Uno-Todo cerrado que puede reflexionar sobre sí para conocerse o desplegarse en lo que ya era por medio de una suerte de anamnesis ${ }^{34}$. Necesitamos pues una grieta, una apertura no interior al sistema, que nos aleje de aquella pseudo-creatividad unidireccional y necesaria, sin facticidad y sin exterioridad del idealismo en sus modulaciones. Como dice Jacinto Rivera de Rosales respecto a este problema del que Hegel también adolece:

[...] Esta posibilidad [...] no cabe en Schelling ni en Hegel, tampoco en el Ser absoluto del Fichte de Berlín, ni en el Urgott del último Schelling. Esta línea que separa las filosofías de la finitud de las filosofías del hen kai pan. Al inicio de la Lógica, Hegel iguala esa nada absoluta al ser, para quitar incluso a ambos todo vestigio de facticidad y fijación. 35

En efecto, si para Deleuze, Schelling muestra la segunda síntesis del tiempo y su consecuente individuación (modo de génesis estática), sin embargo necesita una tercera síntesis que abra precisamente el sistema, y lo abra hacia un afuera o espacialidad intensiva. Que abra al sistema hacia el caos o a la verdadera nada, que aparezca una diferencia al fin, no subsumida ni subordinada por el sistema mismo y su interioridad; o lo que es lo mismo, que inaugure un sistema bautizado por Deleuze y Guattari como caosmos o plano de inmanencia, de tal modo que el cosmos y el caos estén íntimamente unidos y puedan construirse mutuamente, sin superarse ni aniquilarse. Para que el sistema salga de los conductos del poder necesita clamar al caos con todas sus fuerzas para que entre aire fresco. Se necesita que el caos nunca sea eliminado enteramente, que sea un caos del sistema mismo, no ajeno a él. Dicen Deleuze y Guattari en ¿Qué es la Filosofía?:

\footnotetext{
34 Cfr. Schelling, F. W. J.: Las edades del Mundo. [200-202] pp. 169-171.

35 Rivera de Rosales, J.: "Ser y límite en el inicio de la Lógica hegeliana. Reflexiones sobre fundamentación y facticidad" en Turro, S. (ed.) Fonamentació i facticitat en l'Idealisme alemany i la fenomenologia. Barcelona, Societat catalana de filosofia. Institut d'Estudis Catalans, 2007. p. 90.
} 
Tal vez sea éste el gesto supremo de la filosofía: no tanto pensar EL plan(o) de inmanencia, sino mostrar que está ahí, no pensado en cada plan(o). Pensarlo de este modo, como el afuera y el adentro del pensamiento, el afuera no exterior y el adentro no interior. Lo que no puede ser pensado y no obstante debe ser pensado [...].36

Así pues, Deleuze necesita para el sistema una doble rectificación; utiliza, en cierto modo a Schelling para vitalizar la estructura kantiana, pero necesita a Kant para estructurar y localizar un afuera del sistema idealista. En Diferencia y Repetición dice lo siguiente:

Quizás es preciso buscar allí las verdaderas razones por las que Kant, como le reprocharon los poskantianos, se atiene al punto de vista del condicionamiento sin alcanzar el de la génesis. Y si el error del dogmatismo consiste siempre en colmar lo que separa, el del empirismo radica en dejar a lo separado en el exterior; en ese sentido, todavía hay demasiado empirismo en la Crítica (y demasiado dogmatismo en los poskantianos). El horizonte o el foco, el punto "crítico" en el que la diferencia cumple su función de reunir, en tanto diferencia, todavía no se ha asignado. ${ }^{37}$

Por lo tanto, es en un personaje intermedio como Hölderlin -ni romántico ni idealista pero romántico e idealista; kantiano sin serlo, poskantiano sin serlo-donde Deleuze encuentra la fisura del afuera que construye el plano de inmanencia. Una cesura (Zwischen) que nos abre a un por-venir. Un por-venir que no es tanto futuro (que dependería de un presente) como una temporalidad de lo abierto mismo, una temporalidad espacial intensiva (o lugar) que no pasa y que permanece siempre en el "entre", la inmanencia misma entre el caos y el kosmos. Dice Deleuze:

En este sentido, es justo decir que la culminación del kantismo no se encuentra en Fichte o en Hegel sino sólo en Hölderlin, quien descubre el vacío del tiempo puro y, en ese vacío, a la vez, la desviación continuada de lo divino, la fisura prolongada del Yo(Je) y la pasión constitutiva del Yo (moi). ${ }^{38}$

Este tercer tiempo, esta grieta tempo-espacial (Zwischen) como di-stancia (tensión entre estancias), tiempo vacío o frontera del Acontecimiento ${ }^{39}$, lugar donde el tiempo deja de ser una ciclicidad sucesiva atada al movimiento para convertirse en una tensión de desposeimiento, es propuesto por Hölderlin, sobre todo, en dos momentos de su obra íntimamente unidos:

\footnotetext{
36 Deleuze, G. y Guattari, F.: Qu'est-ce que la philosophie? p. 59. Trad. Cast., p. 62.

37 Deleuze, G.: Différence et répétition, p. 220, Trad. Cast. p. 260.

38 Op. Cit., p. 118, Trad. Cast. p. 143.

39 Cfr. Ibidem; y Critique et clinique. Paris: Editions de Minuit, 1993, p. 45.
} 
Por un lado, en el resonar de la diferencia constitutiva Hélade-Hesperia ${ }^{40}$. En el lugar, "entre", la tensión o grieta donde cada diferencia, cada posición del sol o epocalidad, sólo puede comprenderse en relación íntima con su otro. Así, la Hesperia o mundo en el que vivimos sólo puede comprenderse a través de un pasado y afuera radical del que tenemos memoria a la vez que no tenemos constancia empírica de que haya existido tal y como la concebimos, tal y como nos sirve de horizonte. Esto es, sólo podemos comprender dónde estamos frente a una Hélade inconsciente o virtual, un afuera que nos constituye y que, al igual que el "cero" del que hablamos, establece un límite inmanente y una memoria que nos acompaña sin un tope pleno, futuro o cerrado, sin un "uno" que cierre un intervalo y establezca un espacio extenso de partes.

Y por otro lado, esta grieta tempo-espacial hölderliniana aparece implícitamente, actuando, en los ritmos y tonos de Edipo y Antígona tematizados, no por casualidad, en los Ensayos del filósofo-poeta alemán. Dice Hölderlin en sus «Notas a Edipo»:

El transporte trágico es, en efecto, propiamente vacío, y es el más no-ligado.

Por eso, en el rítmico seguirse uno a otro de las representaciones, en el cual se presenta el transporte, se hace necesario aquello que en la medida de las sílabas se llama cesura, la pura palabra, la interrupción contrarrítmica. ${ }^{41}$

Es decir, una palabra, su cesura, la interrupción o aquello que cesa violentamente el ciclo del tiempo-movimiento orgánico y nos enfrenta al afuera, al caos, es lo que nos lanza y nos muestra la grieta que da el sentido. Sin estos afueras no podría haber poema, no podría haber lenguaje, no podría haber siquiera los entes. Pues esta cesura misma, el Zwischen, es el ser: "a la vez lo que tiene que ser pensado y lo que no puede ser pensado"42. A aquello problemático que da qué pensar y hace transmutar todo lo que hay generando otro plano de inmanencia, otra epocalidad, otra imagen de lo que significa pensar y otra materia del ser. Se trata de la grieta que hace y deshace el sistema, que nos abre directamente a un por-venir; a la posibilidad de la creación, de la producción de lo nuevo.

El tiempo, como apunta Deleuze, deja de curvarse y se convierte en una línea recta. Pero no se trata de una línea temporal progresiva sino de un espacio, de una línea fronteriza que hay que recorrer en dos direcciones distintas a cada paso para que las singularidades se repartan a sus lados, para que haya sistema y para que el sistema pueda variar. Esta línea, este entre no es otra cosa que el Istmo de Corinto 43

\footnotetext{
40 Hölderlin, F.: "Carta a Böhlendorf, 4 Dic. 1801, en Hölderlin, F.: Ensayos. Op. Cit.

${ }^{41}$ Hölderlin, F.: Ensayos, Op. Cit. p. 147.

42 Cfr. Deleuze, G. \& Guattari, F.: Qu'est-ce que la philosophie?, p. 59, Trad. Cast. p. 62.

43 Cfr. Hölderlin, F.: Hiperión. O el eremita en Grecia, Hiperión, Madrid, 1976. Comienzo de la obra.
} 
o el Archipiélago 44 a los que Hölderlin señala una y otra vez. La diferencia ontológica, el afuera nunca asimilable o incluyente "dentro" del sistema.

Por lo tanto, y para concluir, podríamos decir que Hölderlin introduce la fisura del afuera que dará lugar tanto a la complejidad constructiva del sistema de Schelling como, a través de Nietzsche y de Heidegger, al pensamiento de Deleuze. Pues un sistema abierto, como sugiere T. Oñate en múltiples escritos ${ }^{45}$, se abre al por-venir, y sólo lo hace en una interrupción que nos obliga a mirar alrededor, a oír lo no audible y ver lo no visible; que nos obliga a considerar el acontecimiento, su virtualidad y su caos antes de la individuación del mismo. De tal modo que no agota lo virtual de los pasados posibles, esenciales para ese por-venir no superatorio, ni progresista, ni anclado en un fin dado de antemano. Es decir, se abre a que podamos construir otros mundos a la vez que podamos hacerlo heredando, diferencial e impropiamente, tanto las ruinas de Hiperión, como la historia de las víctimas (como señala W. Benjamin), de otros mundos y culturas incluyendo los nuestros, así como el acontecer de lo sagrado ausente y descentrado: el afuera mismo. Como dice Deleuze en La imagen-tiempo:

De tal manera que la fabulación sea ella misma memoria, y la memoria, invención de un pueblo. 46

\section{Referencias bibliográficas}

Althusser, L.: Para un materialismo aleatorio. Madrid, Ed. Arena Libros, 2002. BAdiou, A.: Deleuze. El clamor del ser. Buenos Aires, Manatial, 1997.

Bergen, V.: L'ontologie de Gilles Deleuze, Paris, L'Hartman, 2001.

CARrasco, A.: «El sistema de los tiempos y el epos de la historia: Schelling y la historicidad del absoluto.» en Bajo Palabra, Revista de filosofía, II Época, n.4. Madrid, 2009.

Deleuze, G.: Spinoza et le problème de l'expression. Minuit, Paris 1968. Trad. Cast. Spinoza y el problema de la expresión. Barcelona, Muchnik Editores, 1996.

Deleuze, G.: Différence et répétition. Paris, PUF, 1968. Diferencia y repetición. Buenos Aires, Amorrortu, 2002.

Deleuze, G.: Curso sobre Kant, 14/3/78. Kant y el tiempo, Buenos Aires, Cactus, 2008.

\footnotetext{
44 Hölderlin, F.: El Archipiélago, Alianza, Madrid, 1997.

45 Explícitamente en Oñate, T.: "Nietzsche y los griegos. Genealogías de la hermenéutica y la postmodernidad hasta nosotros" en El retorno teológico-político de la inocencia (Los hijos de Nietzsche II), Dykinson, Madrid, 2010. p. 551.

46 Deleuze, G.: Cinéma-2: L'Image-temps. Minuit, Paris, 1985, p. 290. Trad. Cast. La imagen-tiempo. Paidós, Barcelona, 1996, p.294.
} 
Deleuze, G.: Curso sobre Spinoza, 9/12/1980. En medio de Spinoza. Buenos Aires, Cactus, 2003.

Deleuze, G.: \& GuATtARI, F.: Mille plateaux, Capitalisme et schizophrénie tome 2. Paris, Minuit,1980. Trad. Cast.:Mil mesetas, Capitalismo y esquizofrenia 2. Valencia, Pre-textos. 1997.

Deleuze, G.: Cinéma-2: L’Image-temps. Minuit, Paris, 1985. La imagen- tiempo. Barcelona, Paidós, 1996.

Deleuze, G., \& Parnet, C.: Dialogues. Paris: Flammarion, 1996. Diálogos. Valencia, Pre-textos, 1997.

Deleuze, G., \& Guattari, F.: Qu'est-ce que la philosophie? Paris, Minuit, 1991. ¿Qué es la filosofia?, Barcelona, Anagrama, 1993.

Deleuze, G.: Critique et clinique. Editions de Minuit, Paris, 1993. Crítica y clínica. Barcelona, Anagrama, 1996.

Deleuze, G.: L'île Déserte et autres textes. Textes et entretiens 1953-1974. Paris, Minuit, 2002.

DuQue, F.: Historia de la Filosofia Moderna. La era de la Crítica. Madrid, Akal, 1998.

Franco, L.: Gilles Deleuze. Sentido y Acontecimiento. Madrid, Eds. Antígona, 2011.

García, R.: La Anarquía Coronada: La Filosofía de Gilles Deleuze. Buenos Aires, Colihue, 1999.

Goddard, J-Ch.: Mysticisme et folie: Essai sur la simplicité. Paris, Desclée de Brouwer, 2002.

Gualandi, A.: Deleuze. Paris, Figures du Savoir Paris: Les Belles Lettres, 1998.

HeIdegger, M.: La pregunta por la cosa. La doctrina kantiana de los principios trascendentales. Buenos Aires, Ed. Sur, 1964.

Hölderlin, F.: Ensayos. Madrid, Hiperión, 1997. Prólogo, traducción y notas de Felipe Martínez Marzoa.

Hölderlin, F.: Hiperión. O el eremita en Grecia, Madrid, Hiperión, 1976.

Hölderlin, F.: El Archipiélago, Madrid, Alianza, 1997.

Martínez MarzoA, F.: Historia de la Filosofia II. Madrid, Istmo, 1994.

Martínez MarzoA, F.: De Kant a Hölderlin, Madrid, Visor, 1992.

Martínez MarzoA, F.: Hölderlin y la Lógica hegeliana. Madrid, Visor, 1995.

NúÑEZ, A.: Gilles Deleuze. Una ontología estética menor. Madrid, Dykinson, en prensa.

OÑATE, T.: "Nietzsche y los griegos. Genealogías de la hermenéutica y la postmodernidad hasta nosotros" en El retorno teológico-político de la inocencia (Los hijos de Nietzsche II), Madrid, Dykinson, 2010.

PARDO, J. L.: Las formas de la exterioridad. Valencia, Pre-textos, 1992.

PARdo, J. L.: Sobre los espacios. Pintar escribir, pensar. Barcelona, Serbal, 1991. 
Rivera de Rosales, J.: "Ser y límite en el inicio de la Lógica hegeliana. Reflexiones sobre fundamentación y facticidad" en S. Turró (ed.) Fonamentació $i$ facticitat en l'Idealisme alemany $i$ la fenomenologia. Barcelona, Societat catalana de filosofia. Institut d'Estudis Catalans, 2007. pp. 83-99.

Schelling, F. W. J.: Schellings Werke, hrsg. Von M. Schröter, München 1927-1959, reimpr. 1962-1971.

Schelling, F. W. J.: Sistema del idealismo trascendental, Barcelona, Anthropos, 1988. Traducción, prólogo y notas de J. Rivera de Rosales y V. LópezDomínguez.

Schelling, F. W. J.: Las edades del Mundo. Madrid, Akal, 2002.

SimONDON, G.: L'individu et sa genèse physico-biologique. Paris, PUF, 1964.

Toscano, A.: "Philosophy and the Experience of Construction" en J. Norman \& A. Welchman (Eds.): The New Schelling. Continuum, London-New York, 2004. pp. 106-127.

Amanda Núñez García

Facultad de Filosofía

UNED

amandanu@hotmail.com 